\title{
A reestruturação produtiva industrial fluminense: um olhar para as ações do poder público sobre o território e as políticas fiscais na contemporaneidade no município de Rio Bonito- RJ.
}

The productive industrial restructuring in Rio de Janeiro: a look at the actions of the public power over the territory and the fiscal policies in the contemporaneity in the municipality of Rio Bonito-RJ

La reestructuración productiva industrial fluminense: una mirada a las acciones del poder público sobre el territorio y las políticas fiscales en la contemporaneidad en el municipio de Rio Bonito-RJ Restructuration industrielle productive à Rio de Janeiro: un regard sur les actions des autorités publiques dans le territoire et les politiques fiscales contemporaines dans la municipalité de Rio Bonito-RJ

\section{Antonio Carlos Lessa da Rocha}

\section{(2) OpenEdition}

\section{Journals}

\section{Edição electrónica}

URL: http://journals.openedition.org/espacoeconomia/3052

DOI: 10.4000/espacoeconomia.3052

ISSN: 2317-7837

\section{Editora}

Núcleo de Pesquisa Espaço \& Economia

\section{Refêrencia eletrónica}

Antonio Carlos Lessa da Rocha, «A reestruturação produtiva industrial fluminense: um olhar para as ações do poder público sobre o território e as políticas fiscais na contemporaneidade no município de Rio Bonito-RJ. », Espaço e Economia [Online], 11 | 2017, posto online no dia 05 abril 2018, consultado o 02 maio 2019. URL : http://journals.openedition.org/espacoeconomia/3052 ; DOI : 10.4000/ espacoeconomia.3052 


\section{A reestruturação produtiva industrial fluminense: um olhar para as ações do poder público sobre o território e as políticas fiscais na contemporaneidade no município de Rio Bonito-RJ.}

The productive industrial restructuring in Rio de Janeiro: a look at the actions of the public power over the territory and the fiscal policies in the contemporaneity in the municipality of Rio Bonito-RJ

La reestructuración productiva industrial fluminense: una mirada a las acciones del poder público sobre el territorio y las políticas fiscales en la contemporaneidad en el municipio de Rio Bonito-RJ

Restructuration industrielle productive à Rio de Janeiro: un regard sur les actions des autorités publiques dans le territoire et les politiques fiscales contemporaines dans la municipalité de Rio Bonito-RJ

\section{Antonio Carlos Lessa da Rocha}

\section{Introdução}

1 Ao analisar a organização industrial do Rio de Janeiro nos dias de hoje é importante fazermos uma abordagem sobre a reestruturação produtiva que o Brasil desenvolveu a partir, principalmente, dos anos 1990. Anos esses que marcam a entrada do país na globalização, os governos democráticos que se sucederam Fernando Collor, Itamar Franco 
e Fernando Henrique Cardoso, realizaram políticas para que o Brasil se adequasse a nova realidade mundial do neoliberalismo.

De acordo com Araújo (1999) essa nova dinâmica neoliberal que se iniciava nos anos 1990, poderia se dividir em três pontos fundamentais na conjuntura mundial, seriam elas, a globalização, a crise do fordismo e a financeirização da riqueza. Em que a globalização promoveu uma internacionalização da economia como nunca vista anteriormente, isso ocorreu principalmente pela grande velocidade dos fluxos de informação no mundo, facilitando as trocas comerciais entre países.

3 A crise do fordismo marcado pelas crises do petróleo nos anos 70, trouxe para a indústria uma nova forma de produção que é a acumulação flexível, substituindo a produção em massa. Por fincanceirização da riqueza a autora entende como o aumento da capacidade de negócios e força das instituições financeiras, através dos bancos, e das bolsas de valores. Segundo Araújo (1999) essa nova ordem econômica mundial é muito importante para entendermos a reestruturação produtiva que se realiza no Brasil.

4 Como foi dito anteriormente a entrada do Brasil no neoliberalismo marca uma cisão na organização administrativa e política do país, o fim do estado interventor e planejador da economia. Essa mudança vai refletir na redução das políticas protecionistas para as indústrias brasileiras, desenvolvendo uma competição entre o capital industrial nacional e internacional (SABOIA, 2001). Devido a essa competição muitas indústrias fecharam ou passaram pelo processo de fusão, pela necessidade do aumento da competitividade internacional e modernização da produção, de acordo com Araújo (1999).

Outra questão importante dentro dessa restruturação produtiva é à força do local nas negociações com o global, dentro da lógica da globalização, os municípios ganharam uma importância muito grande. De acordo com Santos (1996) e Cano (1997), passamos a ter uma competição entre os municípios que utilizam do seu território como "moedas de troca", em que os respectivos autores chamaram de "guerra dos lugares" e "guerras fiscais".

Com a globalização, o território fica ainda mais importante, ainda que uma propaganda insidiosa teime em declarar que as fronteiras entre Estados já não funcionam e que tudo, ou quase, se desterritorializa. Na verdade, se o mundo tornou possível, com as técnicas contemporâneas, multiplicar a produtividade, somente o faz porque os lugares, conhecidos em sua realidade material e política, distinguem-se exatamente pela diferente capacidade de oferecer às empresas uma produtividade maior ou menor. É como se o chão, por meio das técnicas e das decisões políticas que incorpora, constituísse um verdadeiro depósito de fluxos de mais-valia, transferindo valor às firmas nele sediadas. A produtividade e a competitividade deixam de ser definidas devido apenas à estrutura interna de cada corporação e passam, também, a ser um atributo dos lugares. E cada lugar entra na contabilidade das empresas com diferente valor. A guerra fiscal é, na verdade, uma guerra global entre lugares.

(SANTOS, 1999, http://www1.folha.uol.com.br/fol/brasil500).

6 As empresas escolhem seus locais de acordo com o que os municípios podem oferecer de material e informação avançados, isso de acordo com a dimensão técnica. As empresas também esperam uma série de medidas políticas e administrativas dos munícipios, os mesmos promovem uma série de políticas fiscais, desde a isenção de impostos à doação de terras, flexibilização das trabalhistas e ambientais. Devido esses fatores os municípios passaram a competir entre si, para ter a maior capacidade de atração, pois aqueles locais que não garantem as determinações exigidas por essas empresas ficarão de fora da 
estrutura produtiva, ou seja, ficarão à margem desse processo, tornando-se reservas de lugares.

7 Segundo Cano (1997), o padrão de acumulação da Terceira Revolução Industrial e em conjunto com as políticas neoliberais passaram a desabilitar fiscal e financeiramente os estados nacionais, gerando um forte endividamento do estado. De acordo com o autor, a implementação do "Estado Mínimo" promoveu a descentralização, eliminando a regulação do poder da esfera federal e permitiu uma negociação direta do poder global com o local.

8 Por "guerra fiscal", de acordo com Cano (1997), entendemos uma série de incentivos ficais que são oferecidas as empresas, em várias esferas de poder, desde a União até ao município. Esses benefícios fiscais não são apenas isenções de impostos, podendo ser também doações de terrenos como poder de atrativos para as empresas, são alguns dos mecanismos que o poder público vem promovendo dentro da lógica da reestruturação produtiva.

É óbvio que os esforços no sentindo de alocação de projetos em outras áreas do país devem e podem ser feitos através de programas e projetos detalhados de forma 'mais fina'. Os de recursos privados em buscas de 'vantagens locacionais', ajudaram a aumentar a suicida 'Guerra Fiscal' entre estados brasileiros, promovendo uns verdadeiros leilões de localizações (CANO, 1997, p. 135).

9 Com a disseminação do que estamos chamando de "Guerra Fiscal", de acordo com Cano (1997), enfraquece a estrutura do planejamento nacional, permite uma ampla concorrência entre os lugares, que através dessa política promove uma verdadeira competição ou podemos chamar de leilão, para atrair maior quantidade de empreendimentos privados.

10 Ampliando o pensamento de Cano (1997), podemos analisar o que representou a Constituição Federal de 1988, a capacidade de gestão da União foi descentralizada, possibilitando estados e municípios uma maior capacidade de gestão e planejamento de seus respectivos territórios, marcando uma legislação que se aproximava das políticas neoliberais que se fortaleciam na época. Os municípios ganharam papel de entes federativos, atuando de forma direta, na busca por atrativos que lhes confiam mais lucratividade.

11 Essa nova gestão pós-fordista, foi fundamental para o surgimento dessa "Guerra Fiscal" que analisamos acima. Estados e municípios se tornaram "livres" para realizar eles mesmo suas políticas fiscais, desenvolvendo uma forte concorrência por busca de recursos financeiros, seja por parte de repasse da União ou atraindo indústrias para o seu território.

12 Através dessa realidade fiscal dos municípios e estados, muitas empresas passaram a ser atraídas por esses incentivos, gerando um processo de desconcentração industrial nas grandes metrópoles, principalmente no Rio de Janeiro e São Paulo, indo buscar novos locais para instalar suas estruturas.

13 Segundo Lencioni (2008), analisando a metrópole paulistana, a autora percebe que com essa realidade da reestruturação produtiva, a cidade de São Paulo redefiniu a sua participação na estrutura econômica, deixando de ser exclusivamente uma cidade industrial, mas não perdendo a sua centralidade.

14 Com o processo de industrialização do Brasil, com forte concentração industrial em São Paulo, principalmente nos anos de 1930 e 1970, fizeram dessa cidade ser o "coração" da 
indústria brasileira, mas com a entrada das políticas neoliberais no país e a flexibilização produtiva, acabou estabelecendo um processo de desconcentração industrial a partir dos anos 1990, de acordo com Diniz (2000), e tornando-se terciário por excelência, apresentando um papel de gestão no cenário nacional, superando as demais metrópoles do país.

Cidades de dimensão mais regional e local, ganharam grandes empreendimentos industriais, como por exemplo Resende no Rio de Janeiro, que será analisado mais a frente, ou também Campinas em São Paulo.

Mas de acordo com Lencioni (2008), mesmo com a perda de indústria, motivado pela reestruturação produtiva, as cidades de Rio de Janeiro e São Paulo não perderam a sua centralidade na economia, principalmente São Paulo. Mesmo com a saída de vários parques industriais, a sedes das grandes empresas, bancos, serviços especializados avançados, continuam na metrópole. A metrópole se torna terciária por excelência, com participação de todos os tipos de serviços.

A principal contribuição do conceito de centralização para a interpretação do urbano é que a gestão empresarial dos grupos econômicos e das grandes empresas em rede priorizam a metrópole e, no caso brasileiro, prioriza a metrópole de São Paulo. É no exercício da função central da metrópole, que é de controle do capital, que se adensam os serviços produtivos, os serviços voltados às empresas, muitas vezes denominados de serviços avançados. Daí provém o grande desenvolvimento dos serviços nas metrópoles e, no caso em exame, da metrópole de São Paulo (LENCIONI, 2008, p.14).

17 Além desses serviços especializados, a metrópole continua sendo o principal centro de produção de tecnologia, as cidades de Rio e São Paulo, possuem as principais universidades e os principais centros de pesquisa. Portanto permanece a centralidade dessas cidades na rede urbana brasileira. Elas apresentam papel de comando e controle, principalmente São Paulo, sobre o território nacional, controle este, de gestão.

18 A reestruturação produtiva veio para redefinir o papel das metrópoles no Brasil e no mundo, perderam grande importância industrial com a globalização, mas não perderam a sua centralidade, não deixaram de ser o grande locus de riqueza na estrutura capitalista.

Nesse contexto é que o Condomínio Industrial idealizado pela Prefeitura de Rio Bonito, através de leis locais promoveu uma série de benefícios para empresas que se instalassem no município, atraindo aquelas de capital nacional e internacional.

Posto isto, este artigo tem por objetivo contribuir para a compreensão do processo de reestruturação produtiva, tendo por recorte espacial o município de Rio Bonito, localizado na Região Metropolitana do Rio de Janeiro (Mapa1). A questão central norteadora deste trabalho esta pautada em - Como o município de Rio Bonito se insere no processo de reestruturação produtiva no contexto da metrópole fluminense? 


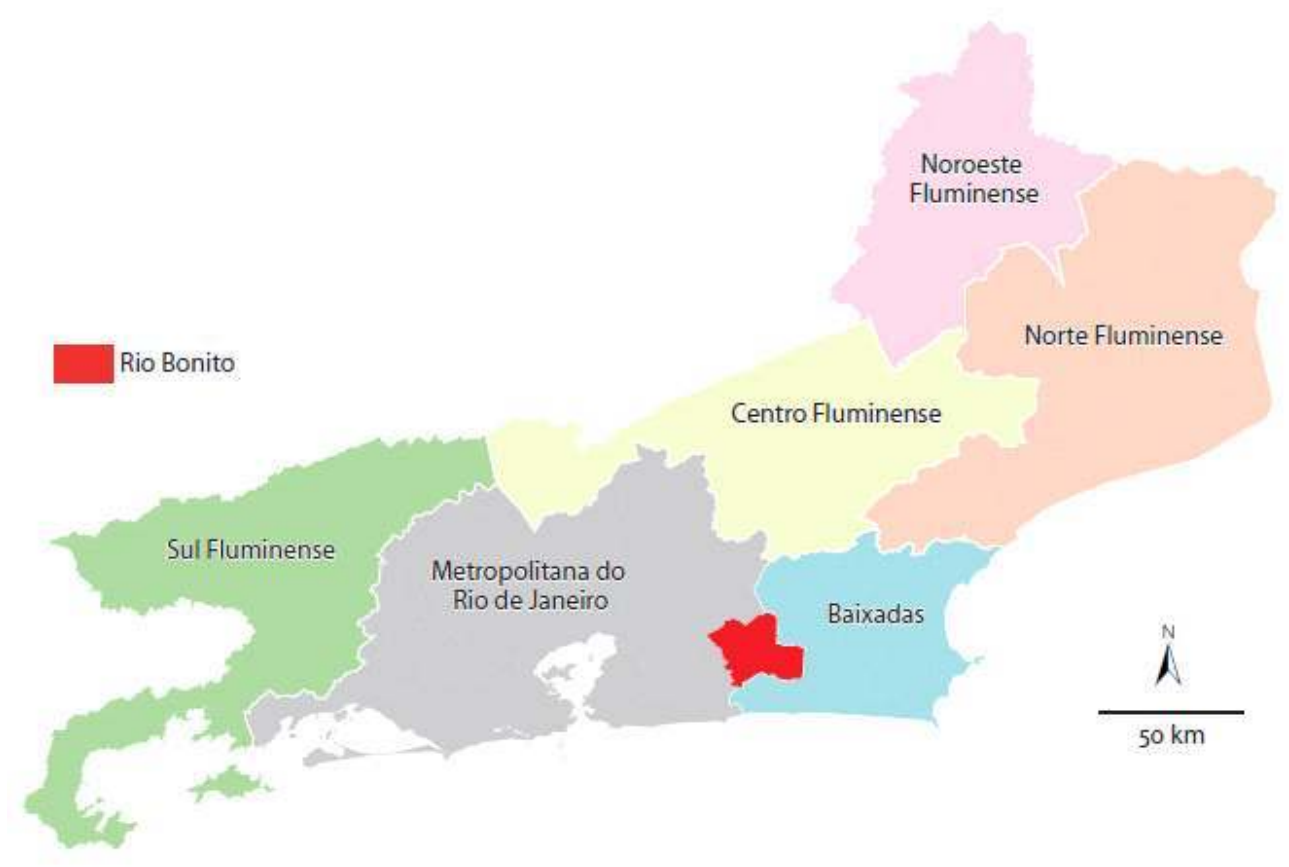

Fonte: Pessôa, 2016.

21 Para atingir o objetivo e responder a questão central, a operacionalização da pesquisa baseou-se em dados de fontes do Censo de 2010 do IBGE e do banco de dados da Prefeitura Municipal de Rio Bonito. Através desses dados foram gerados quadros e tabelas com o objetivo de reforçar a investigação do objeto deste artigo.

Posto isto, o artigo apresenta-se estruturado em duas partes. Na primeira é elaborada uma análise da reestruturação produtiva no território fluminense, enquanto na segunda parte, o município de Rio Bonito é o foco de análise a partir das políticas públicas para atração de indústrias.

\section{Uma breve análise sobre a reestruturação produtiva no território fluminense}

Quando analisamos a organização produtiva histórica do Rio de Janeiro, é possível perceber uma forte concentração de atividades na metrópole e pouco dinamismo econômico no interior, podemos ressaltar a produção sucroalcooleira na região norte do estado, com destaque para Campos dos Goytacazes, e a histórica produção de café no Vale do Paraíba.

Após a mudança da Capital Federal para Brasília em 1960, o Estado do Rio de Janeiro entrou em uma grande decadência econômica por perda de investimentos, motivados principalmente pela mudança da centralidade política do país. Mas ao entrar nos anos 90 , com a adequação do Brasil as políticas neoliberais, ocorre no território fluminense o início de uma reestruturação produtiva na indústria, seguindo dois principais eixos, um em direção ao norte do estado e outro em direção ao Vale do Paraíba. Ao comparar o processo de desconcentração industrial das metrópoles do Rio e São Paulo, Lencioni 
(2015) analisa a expansão da indústria do Rio de Janeiro por eixos e São Paulo de forma areolar.

De acordo com Guichard e Silva (2010), reforçando a ideia desenvolvida por Lencioni (2015), as autoras comparam a expansão da indústria para o interior fluminense com o interior paulista. Segundo as autoras o processo de desconcentração industrial no Rio de Janeiro ocorreu mais tarde, nos ano 90, diferentemente de São Paulo. Esse fato é justificado pela forte polarização que a metrópole exerce no território fluminense, concentrando a grande maioria de capitais e investimentos públicos.

A diferença entre o estado do Rio de Janeiro e o estado de São Paulo é explicada pelas características e pela origem do estado do Rio de Janeiro, que apresenta uma configuração espacial marcada pelos seguintes elementos: alta concentração populacional, econômica e de infraestrutura na região metropolitana, sobretudo na capital; a presença do governo central como forte agente na produção do espaço; a separação institucional entre cidade do Rio e o interior fluminense durante cento e quarenta anos; e uma rede urbana "desequilibrada", com pouco dinamismo das cidades médias (GUICHARD E SILVA, 2010, p. 265).

Dentro desses dois eixos (Mapa 2), aquele que vai em direção ao norte fluminense, seguindo a BR-101, estará ligado principalmente à indústria do petróleo, as cidades que se destacam são Macaé e Campos dos Goytacazes, sendo a última exercendo a maior centralidade (RIBEIRO, 2012). O segundo eixo, indo em direção ao Vale do Paraíba, segue pela BR-116, liderado pela Companhia Siderúrgica Nacional (CSN), a região passou a receber indústrias automobilísticas, a primeira delas foi a Volkswagen-Caminhões no município de Resende.

Mapa 2: Sistemas de Transporte do Estado do Rio de Janeiro

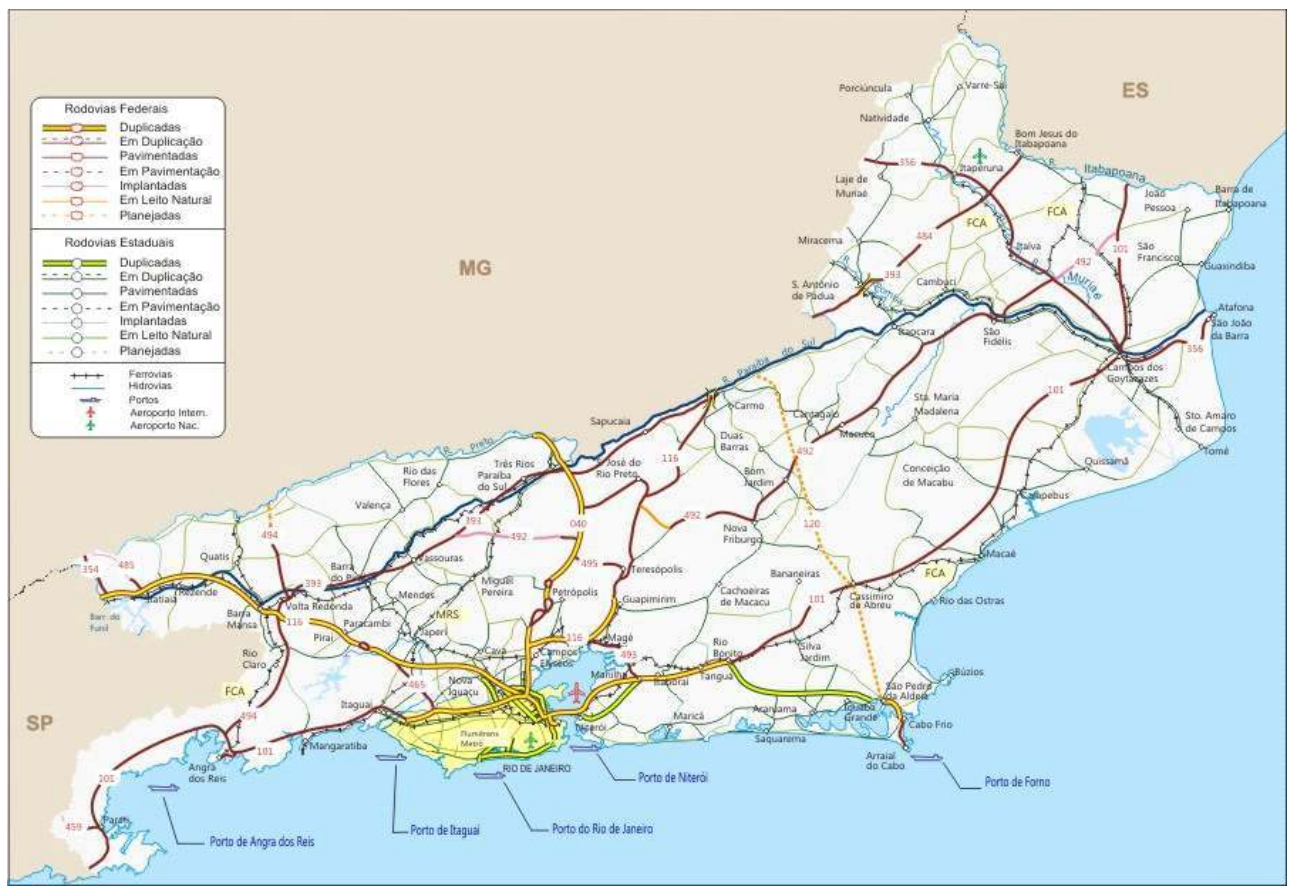

Fonte: Ministério dos Transportes, 2012.

Um fator importante a ser ressaltado, segundo Ribeiro (2012), com o fortalecimento da indústria do petróleo no norte do Estado do Rio de Janeiro começou a ocorrer uma série de municipalizações na região, devido ao recolhimento de royalties pago as Prefeituras 
como compensação da exploração do recurso natural em seu território. Esse surgimento de novos municípios foi muito facilitado pela Constituição Federal de 1988.

Diversos municípios foram criados nos anos de 1990, entre eles estão Armação dos Búzios, Carapebus, Quissamã e Rio das Ostras, todos eles recebem grande quantia de royalties. Carapebus e Quissamã, antigos distritos, participaram da antiga área de produção de cana-de-açúcar no norte do Estado do Rio de Janeiro (PIQUET, 2010), pertencentes ao município de Macaé.

Como verificação desse processo de municipalização para conseguir os recursos do petróleo, desde os anos de 2000, os municípios citados acima possuem mais de $30 \%$ de suas receitas vindas dos royalties, nos anos de 2003 e 2004, e o município de Rio das Ostras chegou a impressionantes $70 \%$ da sua receita vindo da exploração do petróleo, em alto mar (LEMOS E NETTO, 2010).

Segundo Oliveira (2011) o território fluminense, passou a ter novos rumos com essa dinâmica industrial que se formou no Rio de Janeiro a partir dos anos 90 , ocorrendo um fortalecimento dessa reestruturação com duas medidas importantes do Governo Federal: a primeira seria a obrigatoriedade de $60 \%$ dos componentes da Petrobras sejam nacionais, com isso resgatando a antiga indústria de estaleiros na Região Metropolitana do Rio de Janeiro. A segunda medida é a escolha do município de Itaboraí para receber um novo complexo de refinarias de petróleo. Com a criação do COMPERJ é resgatado à construção do Arco Metropolitano (Figura 1) para o escoamento da produção da refinaria até o Porto de Itaguaí, deslocando o trânsito de caminhões do interior da metrópole do Rio de Janeiro.

Figura 1: Arco Metropolitano

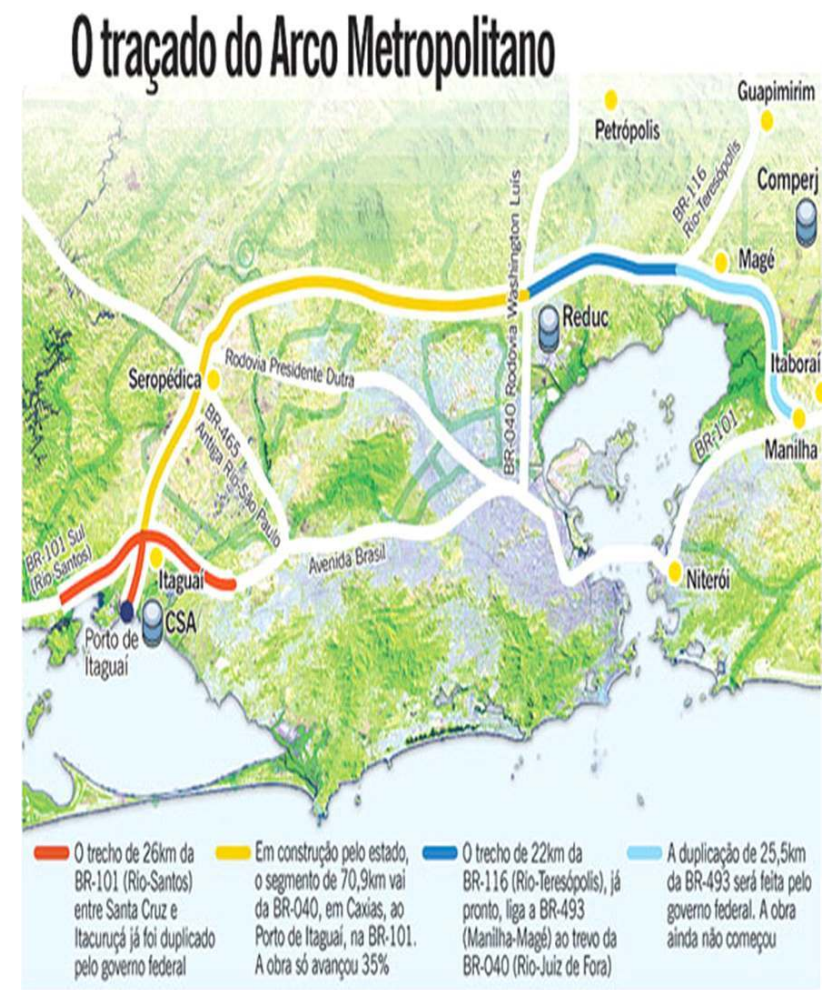

Fonte: http://aaapucrio.com.br/o-que-esperar-do-arco-metropolitano. Acesso em 18/06/16. 
De acordo com essa determinação do Governo Federal de $60 \%$ dos componentes da Petrobras serem nacionais, possibilitou ao Brasil possuir um desenvolvimento industrial no setor produtivo da exploração de petróleo, deixando o país entre os poucos com a capacidade de oferecer os componentes necessários para petroleiras (PIQUET, 2010). No quadro 1 teremos a classificação dos países em relação entre a produção e os fornecedores, para observarmos o posicionamento do Brasil na produção de petróleo. Como foi dito anteriormente, essa determinação foi de grande importância para o resgate de um histórico setor produtivo do estado em Niterói e São Gonçalo, na Região Metropolitana.

Quadro 1: Classificação dos países em relação a produção de petróleo e participação de fornecedores locais

\begin{tabular}{|c|c|}
\hline Categoriad & Exemplos'de países \\
\hline $\begin{array}{l}\text { Pequena produçãoe } \cdot \text { fraca } \text { participação } \cdot \text { de } \\
\text { fornecedores'locais }\end{array}$ & Bolívia·e'Equadord \\
\hline $\begin{array}{l}\text { Grande } \cdot \text { produção } \cdot e \cdot \text { fraca } \cdot \text { participação } \cdot \text { de } \\
\text { fornecedores } \cdot \text { locais } \square\end{array}$ & Nigéria, Venezuelad \\
\hline 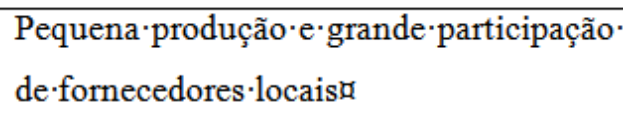 & França e·Itáliaপ̆ \\
\hline $\begin{array}{l}\text { Grande produçãoe grande participação de } \\
\text { fornecedores·locais }\end{array}$ & $\begin{array}{l}\text { Estados' Unidos, } \cdot \text { Noruega, } \cdot \text { Inglaterra } \cdot e \cdot \\
\text { Brasil. } \cdot \text {. }\end{array}$ \\
\hline
\end{tabular}

Fonte: Adaptado de PIQUET (2010).

Seguindo a análise da reestruturação produtiva no território fluminense, segundo Oliveira, Abrantes e Natal (2010), o Estado do Rio de Janeiro possui projetos-âncoras ligados a diversos setores produtivos, como a indústria do petróleo no norte fluminense, o polo metal-mecânico, Petrópolis-Tecnópolis, Complexo de Sepetiba, Polo Gás-Químico de Duque de Caxias. Sendo apenas dois projetos na Região Metropolitana, Complexo de Sepetiba e Polo Gás-Químico de Duque de Caxias.

Ambos os projetos possuem a intenção de desconcentrar da cidade do Rio de Janeiro os respectivos setores produtivos, sendo o Complexo de Sepetiba, em Itaguaí, a construção de todo um complexo portuário para ser a principal entrada de navios no Rio de Janeiro, e o Polo Gás-Químico sendo uma ampliação da estrutura existente da Refinaria de Duque de Caxias.

o projeto de Petrópolis-Tecnópolis, se trata de um grande polo de desenvolvimento de pesquisas, principalmente de software, localizado no município de Petrópolis na Região Serrana do Rio de Janeiro, esse projeto recebeu um forte investimento federal, construindo unidades do LNCC (Laboratório Nacional de Ciências da Computação) e do CNPq (Conselho Nacional de Desenvolvimento Científico e Tecnológico).

De acordo com Piquet (2010) outro grande projeto acontece no território fluminense, fora da Região Metropolitana. No município de São João da Barra, no norte do estado, se encontra um dos maiores investimentos privados do Estado do Rio de Janeiro, o Porto do Açu, construído principalmente com capital nacional (Grupo do Empresário Eike Batista) e sul-africano Anglo American. 
Esse porto tem como objetivo principal o escoamento do minério de ferro vindo de Minas investimento de capital chinês, em que a empresa Wuhan Iron \& Steel (Wisco) decidiu em 2009 a construção de uma siderúrgica no local, mas foi suspensa a construção.

Após essa breve discussão sobre a reestruturação produtiva no Estado do Rio de Janeiro, vamos analisar o exemplo de Rio Bonito dentro dessa lógica que o Brasil e o Estado estão exercendo no território. Vamos perceber como o poder público local vem promovendo uma série de políticas fiscais, para se adequar a essa lógica neoliberal que estamos enfrentando na era da globalização, para atrair diversas empresas.

\section{Políticas públicas para atração de indústrias, dentro da lógica da reestruturação produtiva em Rio Bonito}

Ao passarmos pela BR-101 é fácil reparar uma tentativa de um parque industrial para Rio Bonito, chamado pela Prefeitura de Condomínio Industrial de Rio Bonito, está em uma área situada na BR 101, Km 49, Rio dos Índios, zona rural do $1^{\circ}$ Distrito do referido município, delimitando uma área total de 378900 metros quadrados. No mapa 5 observaremos a divisão distrital de Rio Bonito.

Mapa 3: Divisão de distritos de Rio Bonito

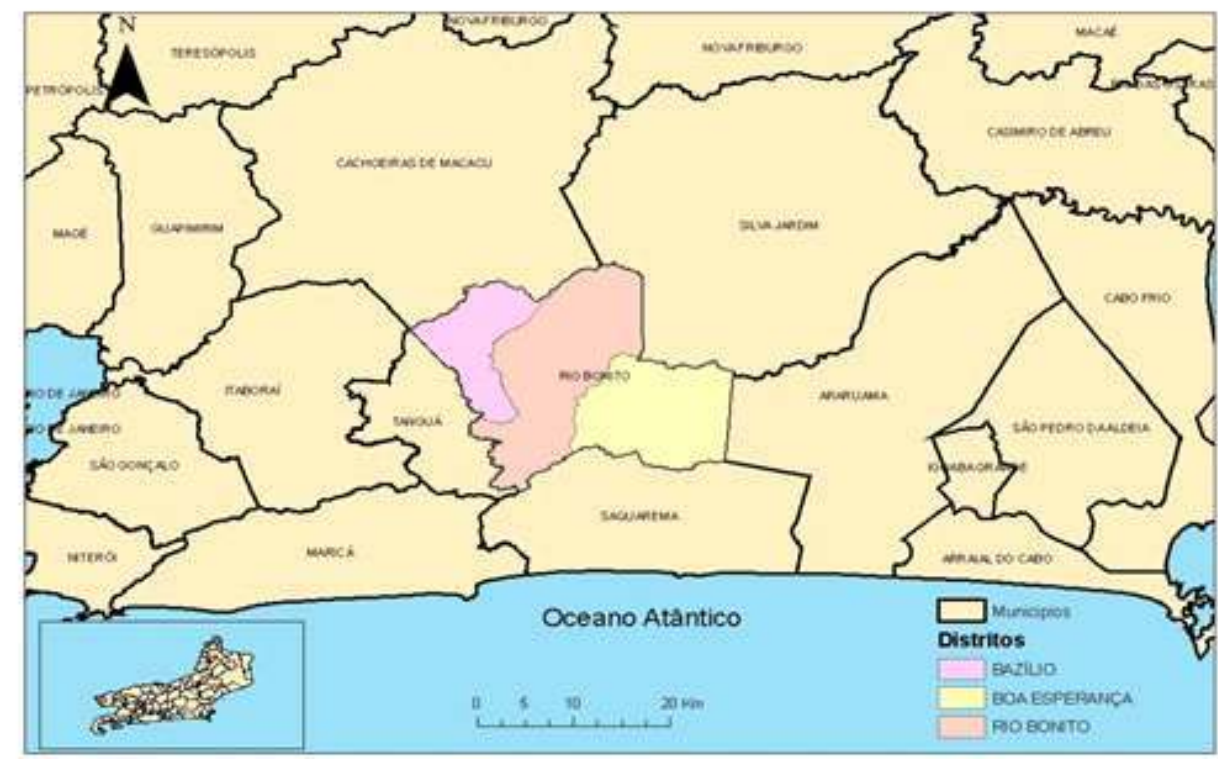

Fonte: Rocha, 2011

A concessão será por um prazo de 20 anos, podendo ser prorrogado por igual período, desde que comprovado a continuidade de sua finalidade, admitindo-se a sua modificação desde que compatível com a área concedida e na forma do artigo $3^{\circ}$ da Lei 715 de 08 de maio de 1998, lei que regulamentou esse projeto da prefeitura. Com relação ao IPTU, os imóveis destinados ao exercício da atividade econômica em geral com, no mínimo, 10 empregados e ampliações iguais ou superiores a $20 \%$ da área construída, gozam de isenção pelo período de 10 anos. 
Esse é um dado direto da própria Prefeitura formalizando a criação desse parque industrial, que tem seu decreto lei de criação em 1998, mas é em 2007 que a primeira empresa se instalou no local, que foi a Nutriara Alimentos, já mencionada, possívelmente interessada pelo ISS a 1\% concedido as empresas que queiram se instalar lá. Em entrevista do então Prefeito José Luiz, "Rio Bonito é uma cidade de reconhecida vocação para negócios, sendo referência na região desde sua fundação" (GUIA RB, 2007, s/p), a partir da fala do então Prefeito de Rio Bonito fica evidente como a implementação do COMPERJ agilizou um processo que estava parado há vários anos. Mas nessa fala do prefeito veremos alguns equívocos, no qual o Condomínio Industrial ainda carece de infraestrutura básica como calçamento.

41 A imagem 1 indica a localização espacial do Condomínio Industrial, a rodovia em questão é a BR-101. As setas na imagem ajudará a nos orientar qual é o sentindo para a Cidade do Rio de Janeiro e o Norte Fluminense, mencionada anteriormente como produtora de petróleo.

Imagem 1: Condomínio Industrial de Rio Bonito

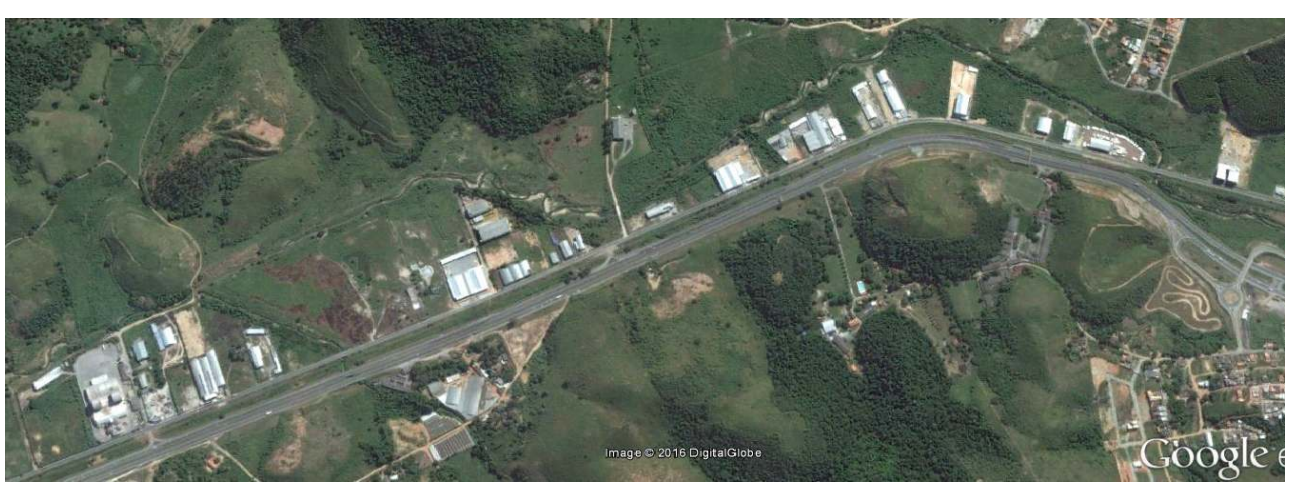

Fonte: Google Earth, 2016.

Outra observação que podemos apontar nesta imagem 1 é a sua localização em uma área rural do município, alterando a dinâmica que existia naquela área, de pequenos sítios para uma nova realidade industrial. Essa questão ajuda a compreender a precária oferta de infraestrutura urbana do local, as ruas receberam calçamento no final de 2014, a única rua calçada era a da Nutriara, a iluminação ainda é bem precária. A infraestrutura relacionada a condições de trabalho para a população também deixa a desejar, pois a localidade possui apenas uma linha de ônibus, dificultando o acesso e a acessibilidade com o Condomínio Industrial.

Um questionamento pode ser feito - Até que ponto essas empresas serão atraídas apenas por essas isenções fiscais, analisando a condição de infraestrutura física desse Condomínio Industrial?

$44 \mathrm{Na}$ imagem 2, está destacada a empresa Nutriara, a maior indústria instalada no Condomínio Industrial. Com isso é a maior responsável pela contratação de mão de obra dos moradores de Rio Bonito, de acordo com a legislação municipal mencionada anteriormente. Cumpre mencionar que ao passar pela BR-101, a referida empresa destaca-se no Espaço/Paisagem da localidade retratando um empreendimento de grande porte. 
Imagem 2: Localização da Nutriara

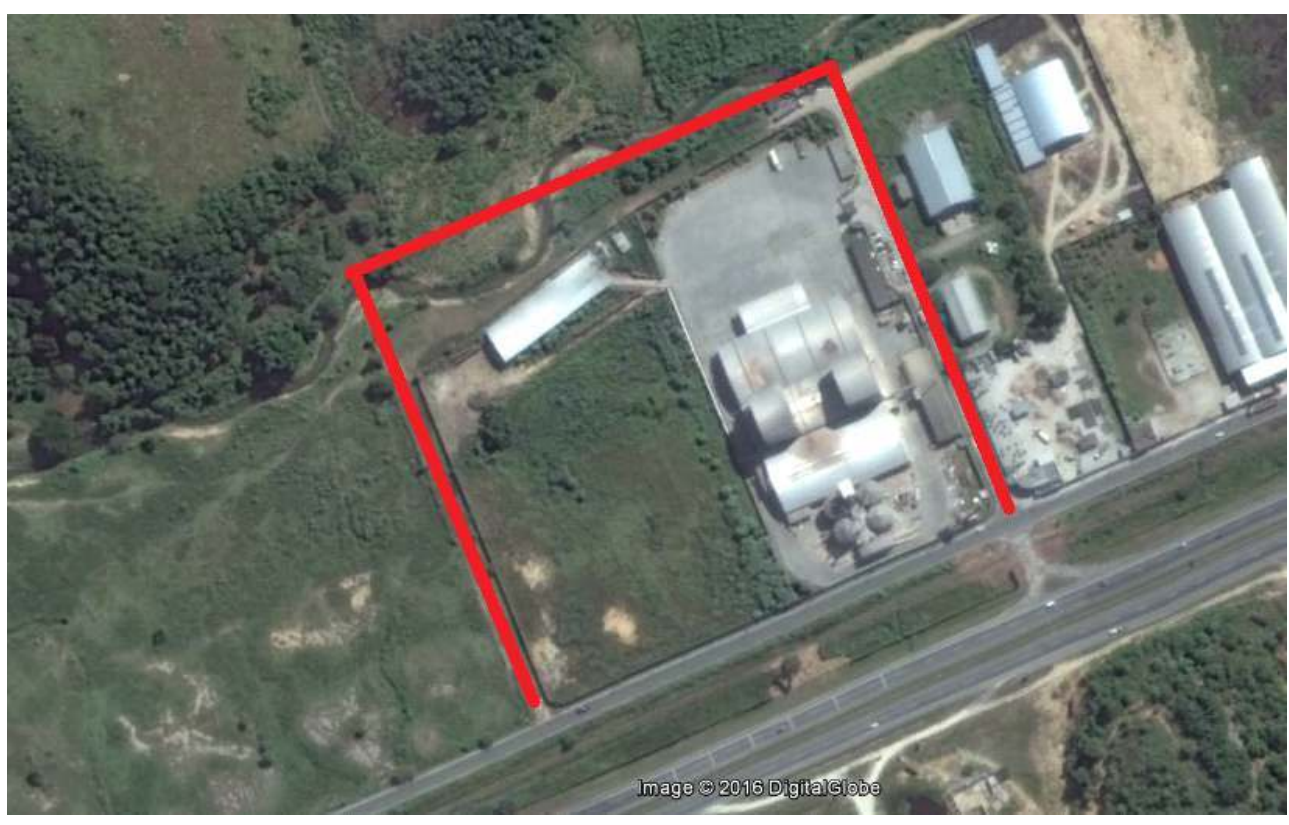

Fonte: Google Earth, 2016.

Apesar de vários problemas de infraestrutura algumas indústrias estão se interessando em se instalar no Condomínio Industrial, justamente nessa ideia de estar próximo do COMPERJ (Complexo Petroquímico do Estado do Rio de Janeiro) e principalmente sem estar em local de trânsito intenso. $O$ Quadro 2 a seguir registra a relação de empresas que chegaram em Rio Bonito até o ano de 2016, suas atividades e a origem do capital das mesmas. 
Quadro 2: Condomínio Industrial de Rio Bonito: Empresas instaladas até 2017

\begin{tabular}{|c|c|c|}
\hline Empresas & |Atividade & |Origem do Capital \\
\hline $\begin{array}{l}\text { Gaipan Soluçōes } \\
\text { Ambientais }\end{array}$ & $\begin{array}{l}\text { Empresa de prestação de serviços de proteção } \\
\text { ambiental, reciclagem de residuos e } \\
\text { subprodutos industriais }\end{array}$ & Brasil \\
\hline $\begin{array}{l}\text { RE-BARS do Brasil } \\
\text { Comércio, Indústria e } \\
\text { Construçôes } \\
\end{array}$ & $\begin{array}{l}\text { Empresa de do ramo de iluminação, fabrica de } \\
\text { material plástico de uso na construção civil. }\end{array}$ & Brasil \\
\hline $\begin{array}{l}\text { M.H Lucas Comércio de } \\
\text { Gás }\end{array}$ & Empresa de comércio de gás & Brasil \\
\hline Nutriara Alimentos Ltda. & $\begin{array}{l}\text { Industria de fabricação de alimentos em geral, } \\
\text { comércio de importação e exportaçăo de } \\
\text { produtos agropecuários }\end{array}$ & Brasil \\
\hline \begin{tabular}{|l} 
Pau-Brasil Comércio e \\
Distribuiçăo de Madeiras
\end{tabular} & Comércio e Distribuição de madeira & Brasil \\
\hline Rio Blocos & $\begin{array}{l}\text { Empresa de construção de blocos de cimentos } \\
\text { e demais produtos para a construção civil }\end{array}$ & Brasil \\
\hline $\begin{array}{l}\text { Metalvix - Indústria } \\
\text { Metalmecânica Vitória }\end{array}$ & Fabricação e montagem de estruturas metálicas & Brasil \\
\hline $\begin{array}{l}\text { Rally de Mangueira } \\
\text { Indústria e Comércio de } \\
\text { Pré-Moldados }\end{array}$ & $\begin{array}{l}\text { Extração de cascalho, fabricação de estruturas } \\
\text { pré-moldadas de concreto armado, em série e } \\
\text { sob encomenda, fabricação de artefatos de } \\
\text { cimento para uso na construção, }\end{array}$ & Brasil \\
\hline \begin{tabular}{|l|} 
Alziservice Servigos \\
Técnicos \\
\end{tabular} & Empresa prestadora de serviços hospitalares & Brasil \\
\hline \begin{tabular}{|l|} 
Aqua Glass Indústria e \\
Comércio de Água \\
Mineral \\
\end{tabular} & $\begin{array}{l}\text { Empresa de engarrafamento e comercialização } \\
\text { de àgua }\end{array}$ & Brasil \\
\hline $\begin{array}{l}\text { Marmoraria Carvalho } \\
\text { Demier, Transformar } \\
\text { Indústria e Comércio } \\
\text { Ltda, } \\
\end{array}$ & Empresa de material de construção & Brasil \\
\hline $\begin{array}{l}\text { PI - Products } \\
\text { International Ltda. }\end{array}$ & \begin{tabular}{|l|} 
Empresa fornecedora de material para a \\
construção civil e exploração de petrôleo
\end{tabular} & Brasil e Noruega \\
\hline Imbiara & Empresa do ramo de sucos industrializados & \begin{tabular}{|c|c|c|} 
Brasil \\
\end{tabular} \\
\hline Legus Containers & $\begin{array}{l}\text { Empresa locadora e vendedora de containers } \\
\text { habitacionais e módulos sanitários disponibiliza } \\
\text { soluçóes }\end{array}$ & Brasil \\
\hline Textura Rio & Empresa de fabricação tintas em textura & Brasil \\
\hline
\end{tabular}

Fonte: Rocha, adaptado da Prefeitura de Rio Bonito, 2017.

Dentro dessa lógica de articulação do global com o local, é bem pertinente ressaltar a presença de empresas de capital estrangeiro, nesse Condomínio Industrial criado pela Prefeitura Municipal. Um exemplo é a empresa PI, um grupo empresarial que está ligado diretamente à indústria do petróleo na região norte fluminense, essa empresa fornece tubulações para as plataformas de exploração em alto mar na Bacia Petrolífera de Campos, outro exemplo que chama significativa atenção é uma empresa com a bandeira de Portugal, mais pertinente é que na fachada não possui nenhum nome da empresa ou ramo em que ela atua.

Vale lembrar a presença da Nutriara, uma empresa de capital nacional em território de Rio Bonito, esta mesma unidade localizada no Condomínio Industrial também de abrangência nacional, pois abastece o mercado externo da Região Sudeste, principalmente para a Região Sul. São exemplos de como funciona a reestruturação produtiva, em um município que desenvolve uma política de isenção fiscal, atraindo empresas de capital nacional e recentemente de capital internacional, em um município que possui pouco mais de 55 mil habitantes.

No ano de 2014 a Prefeitura e a Câmara dos Vereadores aprovaram uma nova lei (nº 1914 de 14 de março de 2014) que regulamentava o Condomínio Industrial, na qual os anos de isenção fiscal foram ampliados para 30 anos de isenção de IPTU para a empresa que se instale no local. Outro ponto importante dessa lei é a criação de um conselho permanente para a negociação da Prefeitura com as empresas, reforça a ideia que os municípios hoje negociam diretamente com as empresas muitas vezes sem passar pela esfera estadual ou federal. 
Segundo a lei municipal o Contrato Social que as empresas devem ter com o município é a contratação de mão de obra de moradores de Rio Bonito, essa contratação está relacionada ao metro quadrado que a empresa ocupa no Condomínio Industrial, quanto maior for a área maior será a porcentagem de trabalhadores contratados que residem no município.

Analisando essa questão sobre os trabalhadores locais das cidades em que as empresas se instalam, de acordo com Saboia (2001), o autor faz uma análise comparando a desconcentração da indústria no Brasil com a qualificação profissional da mão de obra, em que as indústrias de mais alta tecnologia ainda permanecem nos grandes centros econômicos, Rio de Janeiro e São Paulo, ele também aponta uma ida de alguma dessas empresas para a Região Sul, principalmente o Paraná.

51 Em compensação a grande parte das empresas que migraram para outras regiões do Brasil, principalmente o Nordeste, eram empresas que a necessidade de uma mão de obra qualificada era bem menor, foram justamente atraídas pelos incentivos fiscais e pela grande quantidade de mão de obra barata, muito relacionada à qualificação profissional.

2 Mesmo o município de Rio Bonito integrando o Estado do Rio de Janeiro, localizado na Região Metropolitana fluminense, essa análise em relação à atração de empresas relacionadas à qualificação profissional, também se observa no município, em que as empresas que chegam à cidade, irão apenas absorver a mão de obra local de baixa qualidade, pois Rio Bonito possui um IOEB em 3,9, bem abaixo da média nacional que é 5,0 . Através desse dado educacional, é possível perceber que o poder de atração de empresas do município, é quase que exclusivo para com as indústrias que não necessitam de muita mão de obra de alta qualificação profissional, lembrando que os técnicos que ocupam cargos mais especializados, geralmente não são locais, são de outros estados ou de importantes capitais brasileiras, com melhor formação educacional e com experiência.

Sobre essa questão foi realizado em 2013 uma entrevista com o Presidente da Câmara dos Vereadores, questionando justamente sobre a qualificação profissional. O que foi apontado como meta de Governo é a qualificação profissional do morador de Rio Bonito, segundo ele atualmente se encontra parcerias com o Governo do Estado, para trazer um polo universitário e uma FAETEC, na qual a prefeitura concederia os terrenos a serem construídos, também se inclui nessa perspectiva uma instalação dos cursos do SENAI, ainda em fase de negociação de tais projetos. De fato mesmo é a doação desses terrenos, para isso a prefeitura criou mais duas secretarias, sendo elas Projetos e Gestão e Desenvolvimento Econômico, segundo ele a nova gestão tem consciência que se não investir na profissionalização do rio-bonitense, o município vai ficar a retaguarda em relação aos municípios que investem no setor educacional.

4 Questionado sobre a falta de atração de empregos, fazendo com que aqueles que possuem ensino superior saiam da cidade para trabalhar, o então Presidente da Câmara dos Vereadores aponta que a Prefeitura estaria resgatando um antigo plano de parque industrial, no qual eles irão chamar de Cidade Industrial, para atrair empresas e fazer que essa mão de obra qualificada permaneça em Rio Bonito. $O$ vereador reconhece a falha do poder público na falta de investimentos na qualificação profissional.

Sabemos que o Condomínio Industrial peca nesse aspecto, impedindo a presença de empresas, o município mal oferece mão-de-obra, apenas a braçal e nem a instalação, o incentivo fiscal simplesmente não adianta, já que as empresas terão um gasto de importar mão de obra e produzir infraestrutura para ela mesma. 


\section{Para concluir}

Mínimo" e a flexibilização de leis trabalhistas, a partir dos anos de 1990, a era da globalização também proporcionou uma flexibilização produtiva. Não foram apenas os incentivos fiscais que apenas facilitaram a reestruturação produtiva no Brasil e no mundo, os incríveis avanços tecnológicos, como transporte e comunicação, também foram fundamentais para que alguns setores industriais se descolassem das grandes metrópoles para cidades médias e pequenas, facilitando as economias de aglomerações e as externalidades dessas cidades.

58 Através dessa lógica da reestruturação produtiva, podemos observar como o território fluminense se modificou, indústrias passaram a se instalar em localidades em que antes não era viável, devido à distância da cidade do Rio de Janeiro, sendo o principal centro consumidor e maior qualidade de infraestrutura, além dos incentivos oferecidos pelas prefeituras, através de isenções fiscais.

59 Com essa nova estrutura produtiva, percebemos que o Estado do Rio de Janeiro possui dois principais eixos industriais, ao norte ligado a exploração de petróleo e ao sul ligado a indústria siderúrgica e automobilística, uma mais antiga, que gerou economias de aglomeração e outra mais recente, com características pós-fordista, com pouco emprego de mão de obra, fazendo desta Região do Vale do Paraíba, uma das mais importantes do território fluminense.

60 Em uma escala local o artigo apresentou como o município de Rio Bonito, se insere nessa nova realidade territorial fluminense. A Prefeitura Municipal cria uma área destinada exclusivamente para a atração de indústrias, promovendo uma série de incentivos fiscais, para compensar uma série de ausências de infraestrutura física e social, e nas proximidades de municípios que apresentam atividades industriais e de serviços, como São Gonçalo, e o próprio núcleo da metrópole, a capital fluminense. São complementariedades regionais, que extrapolam em direção as Baixadas Litorâneas e Norte Fluminense nos quais municípios como Cabo Frio, Rio das Ostras, Macaé, entre outros, se inserem nestas mesmas atividades.

61 Devemos reforçar como o enfraquecimento do poder público em escala nacional e os avanços em tecnologia, fez reforçar a direta comunicação do global com o local. Como foi demonstrado neste artigo, Rio Bonito possui em seu território investimentos diretos de capital internacional, através de empresas nacionais, ligadas a indústria do petróleo do norte fluminense.

62 Para finalizarmos poderíamos lançar uma questão para indagações futuras: As políticas públicas empreendidas em escala local, diante da crise econômica por qual vem passando o Estado do Rio de Janeiro e seus municípios terão condições de manter esses novos empreendimentos e seu Condomínio Industrial?

Espaço e Economia, 11 | 2017 

estabelece nas escalas nacional, regional e estadual?

\section{BIBLIOGRAFIA}

ARAUJO, Tânia Bacelar. Brasil nos anos noventa: opções estratégicas e dinâmica regional. In: Estudos Urbanos e Regionais, Pernambuco, no 2, 1999.

CANO, Wilson. "Concentração e desconcentração econômica regional no Brasil: 1970/95”. Revista Economia e Sociedade, Campinas, Unicamp, n.8, jun. 1997.

DINIZ, Clélio Campolina. Impactos Territoriais da Reestruturação Produtiva. In: RIBEIRO, Luiz César de (org.) O Futuro das Metrópoles: desigualdades e governabilidade. Rio de Janeiro; Revan: Fase, 2000, p. 21-62.

GUICHARD, Désirée e SILVA, Catia Antônia da. In: SANTOS, Ângela Moulin S. Penalva; MARAFON, Glaucio Jose e SANTANA, Maria Josefina Gabriel (orgs.). Rio de Janeiro: Um olhar socioespacial. Rio de Janeiro: Editora Gramma, 2010, p. 259-277.

LEMOS, Livaldo Miranda; NETTO, Jayme Freitas Barral. In: SANTOS, Ângela Moulin S. Penalva; MARAFON, Glaucio Jose e SANTANA, Maria Josefina Gabriel (orgs.). Rio de Janeiro: Um olhar socioespacial. Rio de Janeiro: Editora Gramma, 2010, p. 279-297.

LENCIONI, Sandra. Concentração e Centralização das atividades urbanas: uma perspectiva multiescalar. Reflexões a partir do caso de São Paulo. Revista de Geografia Norte Grande. , v.39, p.7 - 20, 2008 . Urbanização difusa e a constituição de megarregiões. In: e-metropolis: Revista Eletrônica de Estudos Urbanos e Regionais. Rio de Janeiro, 2015, no 22, p. 6-15.

OLIVEIRA, Alberto; FILHO, Gilberto Abrantes; NATAL, Jorge. In: SANTOS, Ângela Moulin S. Penalva; MARAFON, Glaucio Jose e SANTANA, Maria Josefina Gabriel (orgs.). Rio de Janeiro: Um olhar socioespacial. Rio de Janeiro: Editora Gramma, 2010, p. 39-77.

OLIVEIRA, F. J. G. Políticas e planos territoriais nas escalas metropolitanas e regionais: análise das mudanças no Rio de Janeiro. In.: Anais do XIV encontro nacional da Anpur, Rio de Janeiro, Anpur, 2011.

PIQUET, Rosélia. In: SANTOS, Ângela Moulin S. Penalva; MARAFON, Glaucio Jose e SANTANA, Maria Josefina Gabriel (orgs.). Rio de Janeiro: Um olhar socioespacial. Rio de Janeiro: Editora Gramma, 2010, p. 79-99.

RIBEIRO, Miguel Ângelo « Transformações sócio-econômicas e mudanças na rede de localidades centrais no Rio de Janeiro: o papel de Campos dos Goytacazes, Macaé e Itaperuna (1966-2007) ", Espaço e Economia [Online], 1 | 2012, posto online no dia 15 Abril 2013, consultado o 25 Maio 2016.

SANTOS, Milton. O retorno do território. In SANTOS, Milton; SOUZA, Maria Adélia A.; SILVEIRA, Maria Laura. (org's). Território: globalização e fragmentação. São Paulo: HUCITEC, 1996, 3ª ed., p.15-20 
. Guerra dos Lugares. In: Folha online: Brasil 500. http://www1.folha.uol.com.br/

fol/brasil500, 1999. Acesso 17/06/16.

\section{RESUMOS}

Este artigo tem como objetivo contribuir para a compreensão do processo de restruturação produtiva, nos principais centros econômicos brasileiros, entre eles a cidade Rio de Janeiro. Esses centros, no atual contexto da globalização, passaram por uma nova organização espacial, onde seu poder de atração de capitais industriais de menor nível tecnológico deixou de ser central. Os municípios médios e pequenos, principalmente passaram a ter uma força de atração de setores industriais de vários setores. Para fortalecer esse debate foi elaborada uma análise da construção de um Condomínio Industrial no município de Rio Bonito, dentro dos moldes da reestruturação produtiva, desenvolvendo uma política de incentivos fiscais para a atração de empresas.

Contributing to comprehension of the productive restructuring process in major Brazilian economic centers, including the city of Rio de Janeiro, is this paper's main goal. Inserted in globalization's current context, these centers undertook new spatial arrangements, ceasing to play a central role in attracting industrial capital of lower technological level. Thus, smaller cities became attractive to several industrial sectors. In order to substantiate this observation, the construction of an industrial condominium in Rio Bonito is analyzed concerning productive restructuring aspects, in which a policy of tax incentives for attracting companies investments is developed.

Este artículo tiene como objetivo contribuir a la comprensión del proceso de reestructuración productiva, de los principales centros económicos brasileños, entre ellos la ciudad de Río de Janeiro, en el actual momento de la globalización. En esta nueva organización espacial, los grandes centros tradicionales, perdieron importancia y fueron relevados por los municipios medios y pequeños, en la atracción del sector industrial y tecnológico, principalmente a través de incentivos fiscales. Para fortalecer ese debate se elaboró un análisis de la construcción de un Condominio Industrial en el municipio de Rio Bonito, dentro de los moldes de la reestructuración productiva, desarrollando una política de incentivos fiscales para la atracción de empresas.

Cet article vise à contribuer à la compréhension du processus de restructuration productive, dans les principaux centres économiques brésiliens, dont la ville de Rio de Janeiro. Ces centres, dans le contexte actuel de mondialisation, ont connu une nouvelle organisation spatiale, où leur pouvoir d'attraction des capitaux industriels de moindre niveau technologique n'est plus central. Les municipalités moyennes et petites, principalement, ont commencé à exercer une force d'attraction des secteurs industriels de plusieurs secteurs. Pour renforcer ce débat, a été élaborée une analyse de la construction d'un condominium industriel dans la municipalité de Rio Bonito, dans le cadre de la restructuration productive, en développant une politique d'incitations fiscales pour attirer les entreprises. 
ÍNDICE

Mots-clés: restructuration productive, politiques territoriales, Rio Bonito, condomimium industriel, État de Rio de Janeiro.

Palavras-chave: reestruturação produtiva, políticas territoriais, Rio Bonito, Condomínio Industrial, Estado do Rio de Janeiro.

Palabras claves: Reestructuración productiva, políticas territoriales, Rio Bonito, Condominio industrial, Estado de Rio de Janeiro.

Keywords: productive restructuring; territorial policies; Rio Bonito; industrial condominium; Rio de Janeiro state.

\section{AUTOR}

\section{ANTONIO CARLOS LESSA DA ROCHA}

Mestrando em Geografia PPGEO-UERJ

a.c.l.rocha@hotmail.com 